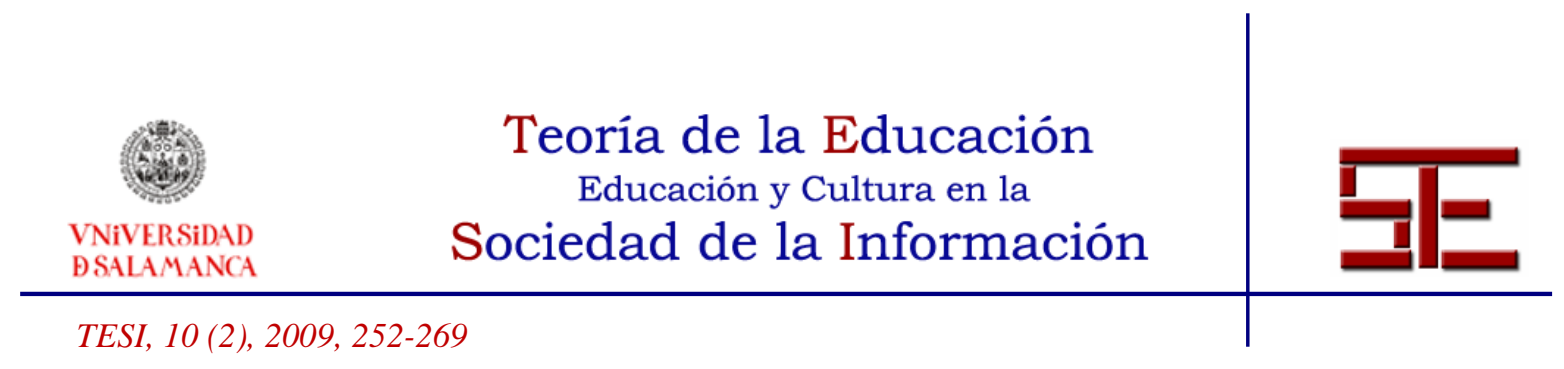

\title{
DIGITALIZANDO LAS TRADICIONES: CONTENIDOS ETNOGRÁFICOS APLICADOS A CONTEXTOS URBANOS Y REGIONALES IRLANDESES.
}

Resumen: El artículo expone los últimos progresos en las actividades de investigación aplicadas en el departamento de Folklore y Ethnology del University College Cork con particular referencia a las implicaciones del uso de las tecnologías informáticas y digitales en ambientes de trabajo de campo. Destacando el caso del establecimiento de un centro Multimedia para la Etnología Urbana y Regional como un archivo virtual, el estudio explora la dimensión pedagógica relativa a los contextos educativos adultos y no tradicionales. El artículo hace referencia a la política de financiación gubernamental, especialmente su aplicación al desarrollo interdisciplinario de ayudas de auto aprendizaje a través del uso del irlandés como lengua minoritaria. Además, sitúa la discusión dentro de las perspectivas teóricas más amplias de la cultura popular y los medios de comunicación para explorar las potencialidades y los límites existentes e inesperados relativos a la emergencia de la sociedad de la información y la comunicación.

Palabras clave: tecnologías, Sociedad de la Información, etnografía, cultura, educación

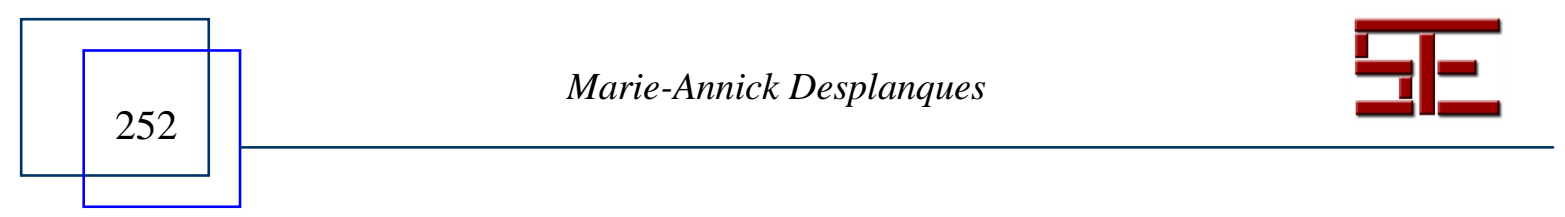




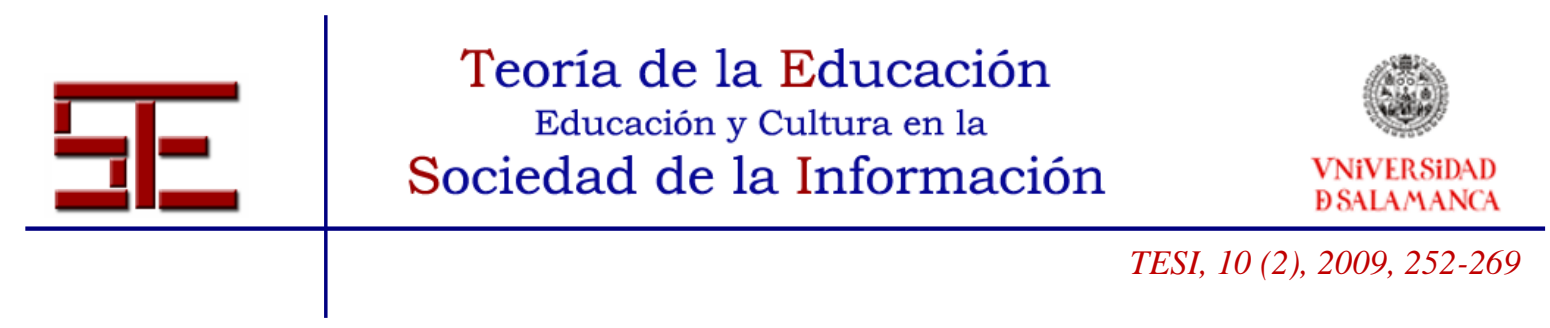

\title{
ARE THE INFORMATION TECHNOLOGIES CHANGING POLITICS? CASE STUDY IN GALICIA
}

\begin{abstract}
In the industrial society, politicians had to command the language TV since the intensity of the reaction was more important than the length of the message. They had to make categorical statements. In the Information Society with information and communication technologies (TICs), this changes to a great extent due to pluralism and the fact that more people make themselves heard. Blogs appear as a way to give opinion and information, and can be considered as an alternative form of expression -blogs give different views on news ignored by the main media-. Activists, political parties, organizations and citizens use websites, blogs or wikis as a means to insist and create opinion. TICs and cooperative tools of Web 2.0 increase people's interest in politics, individual commitment and participation and cause political mediators to disappear. This paper presents a reflection on the impact of TICs on the theory of politics, and the results of a quantitative analysis of cases from the observation of how TICs are used on the social platform "Nunca Máis", as well as by the autonomous government Xunta de Galicia, the Parliament of Galicia and the political party Bloque Nacionalista Galego.
\end{abstract}

Key words: E-Government, E-Democracy, Civic Participation, Information Society, Political Activism.

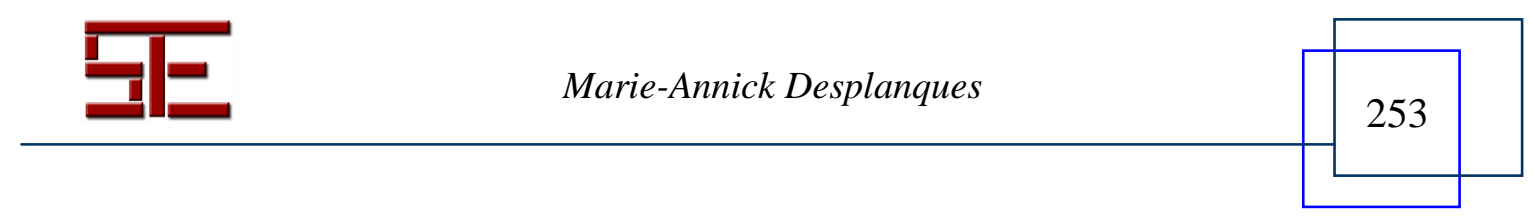




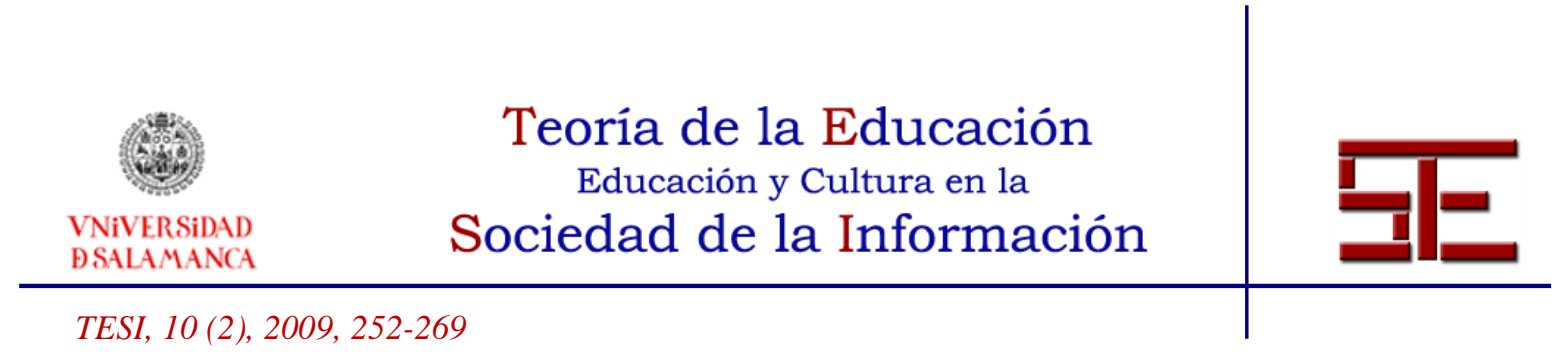

\title{
DIGITIZING TRADITION: ASPECTS OF THE APPLIED DIMENSION OF URBAN AND REGIONAL ETHNOGRAPHY IN IRISH CONTEXTS.
}

\author{
Marie-Annick Desplanques \\ MA.Desplanques@ucc.ie \\ University College Cork.
}

The turn of the millennium was a significant departure for the study and practice of ethnography at University College Cork. The applied dimension of ethnology scholarship in this institution saw new beginnings. These coincided with new directions in the research agenda and resulted from accessibility to new emerging digital and computer technologies. Henceforth these technologies enabled progress and developments in the collection, archiving and dissemination of material pertaining and relevant to traditional and popular culture and its processes. Similarly and in parallel, technological innovations in the twenty first century also engendered new creative expressions and therefore generic categories relevant to informal yet coded and ritualized modes of communication such as "texting" or "blogging" which were interdependent on communities of people using computers and the internet. These communities revolved around such networks as "Bebo", popular with teenagers in Ireland and beyond and the more global network commonly known as "Facebook" or "Myspace" to name but a few while others, literally virtual communities, are based on interfaced communication through participation in online games (Wellman and Gulia, 1999; Sóleyjarson, 2008). Interestingly, although beyond the actual scope of this present paper, such issues as the ethnographic potentials offered by these developments linking technologies and communities partially informed reflection around the content of a contribution I gave to an international symposium entitled "Digitizing Ethnography", which I organized at University College Cork with my colleague Cliona O'Carroll in 2006.

\section{1. - DIGITIZING ETHNOGRAPHY SYMPOSIUM}

Gathering expertise and expanding on international and interdisciplinary perspectives in human and social sciences, the symposium, addressed the particular issues and themes mentioned above as well as others pertaining more specifically to new developments and applications of digital technologies in educational contexts and environments. Participant contributors, from academic institutions in Finland, Scotland, Galicia and Ireland were from various research and teaching backgrounds ranging from Folklore

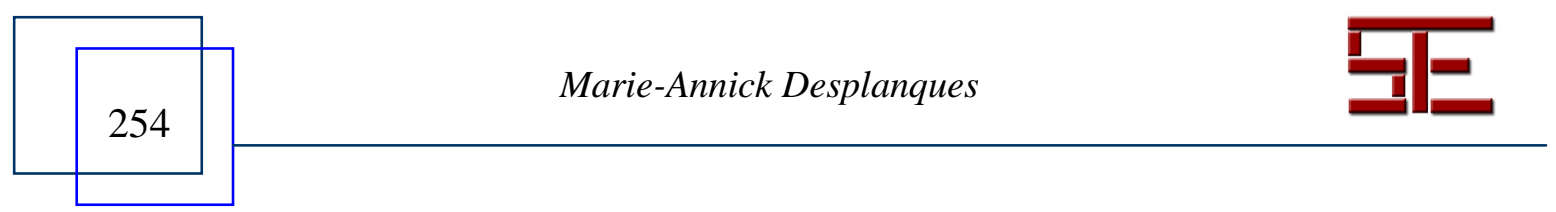




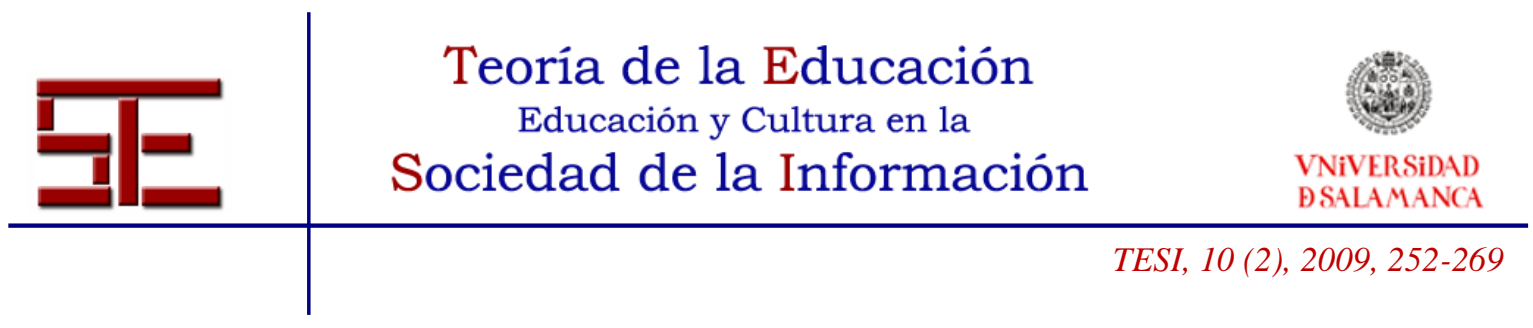

and Ethnology to Cultural Geography, Sociology and Art History. Multimedia presentations were given to an audience of academic as well as community researchers and workers from similar backgrounds as the presenters and from all over Europe and North America. All had a common interest and were actively involved in applied research using information technologies which addressed and considered issues relevant to the archival and educational uses of cultural primary documents, in aural, visual or textual formats. My own contribution focused on the recent establishment of a virtual Multimedia Centre for Urban and Regional Ethnology (MCURE). I considered issues relating to the digitization of ethnography with specific reference to the abovementioned modes of communications yet within a more generalized context of the impacts of information technologies in society1.

The symposium highlighted specific synergies namely between MCURE and the work of Carlos Macía Arce with SINDUR (Information Society in Urban and Regional Development) which partially investigates the uses of Folklore material as a catharsis for the introduction of new information and communication technologies in the rural district of Brion in Galicia. Similar issues relative to digital and information / communication technologies in relation to expressions of ethnicity, minority languages or peripheral cultural spheres were also addressed by John Shaw of the School of Scottish Studies in Edinburgh. Other contributions focused on issues attached to the digitizing and organizing of textual archival material generically defined as in the case of the digital database of Finnish, Carelian and Ingrian folk poetry in the so-called Kalevala-metre, based on the grand opus of Finnish folklore, SKVR "The Ancient Poems of the Finnish People" discussed by Jukka Saarinen, Senior Researcher at the Folklore Archives of the Finnish Literature Society. The digitization processes and technologies associated and used for various formats of early and more modern analog archival ethnographic sound recordings were also prsented by Jukka Saarinen. The issues raised were confirmed and reflected the Irish Folklore Commission material situation as discussed by Ríonach uí Ógáin, lecturer and archivist with the then Department of Irish Folklore at University College Dublin recently renamed the Delargy Centre for Irish Folklore.

Contemporary material in more immediate fieldwork and archival contexts using digital ethnographic sound recordings were also discussed by Cliona O' Carroll of the Department of Folklore and Ethnology at University College Cork with specific reference to information technologies, as they applied to the collection and editing of such material for radio broadcast as part of a project (Desplanques and O' Carroll,

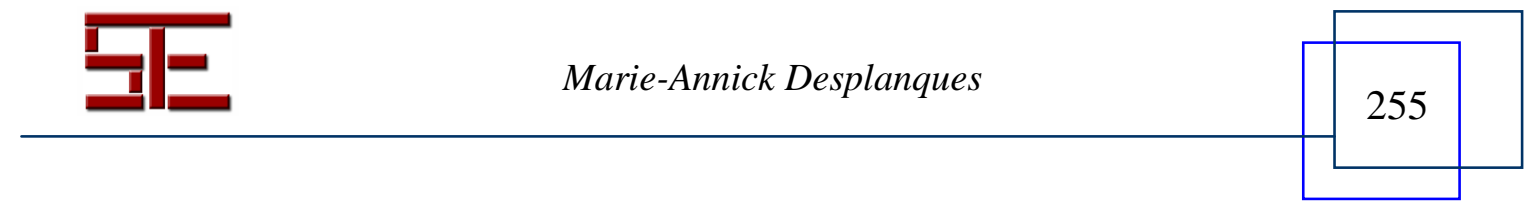




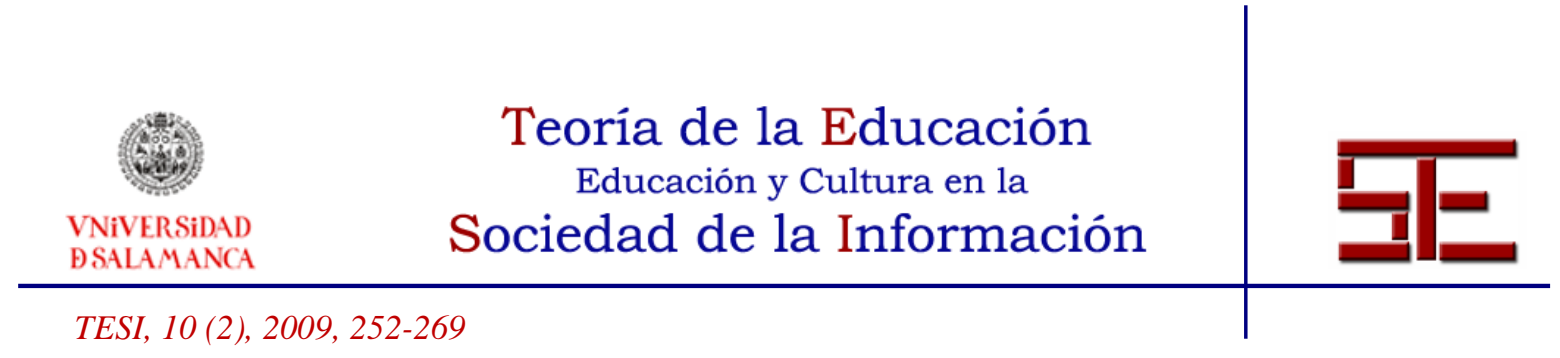

2006), for which she was commissioned by the Northside Folklore Project2. Similar issues relative to one of the first examples in Ireland of an integrated 'interview to internet' 3 project concerned with the digital collection, preservation, interrogation and online retrieval of audio material. These were addressed by Piaras Mac Éinrí, a geographer at UCC whose main research interests in the general area of migration studies focus on issues of immigration and integration in Ireland today and are therefore inclusive of dynamics relative to ethnicity. A case study in the digitization of visual material was presented by JamesCronin of the Department of Art History at University College Cork. He specifically addressed concerns and interests in the application of new communication technologies to teaching and virtual multi-media learning environments within History of Art. His contribution also explored aspects of 'digital exclusion' in adult education, a point which was indeed common to and echoed by most contributions which overall also addressed the extent and limits of the impact of digital technologies on the so-called democratization factors and effects of information society.4

As most contributors agreed, there is indeed a "democratizing" dimension attached to the "proliferation" of digital communication technology, to the extent that we now consider the notion of an information society in relation to or as generated by these technologies. However, the democratizing effect is in no way universal and its boundaries, maybe geographic, economic or social, or a combination of those aspects resulting in excluding people affected by these criteria.

It is interesting to note that no computer scientists actually attended the symposium, although invitations had been issued to academics or technicians either involved in fundamental research or its "multimedia" applications. This unfortunate occurrence possibly deprived the symposium of an extra dimension in the debates that ensued and potentially of specific technical information that may have benefited all present. Yet, their noted absence paradoxically reinforces a point in terms of the relative accessibility of technology to non-scientific academics researchers. However one must of course realize that it is computer scientists' researches into the "user-friendliness" quality in their designing of the micro-technologies and hardwares that ultimately enable others, nonspecialists, to use and partake in the software and programme applications. None of the people present had degrees in computer science, yet all had been expertly involved in the design and uses of programmes and software which furthered and enhanced research, teaching and learning in humanities and social sciences.

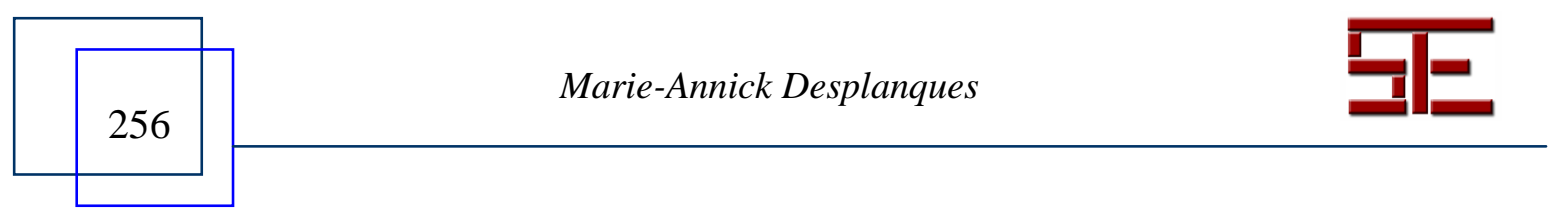




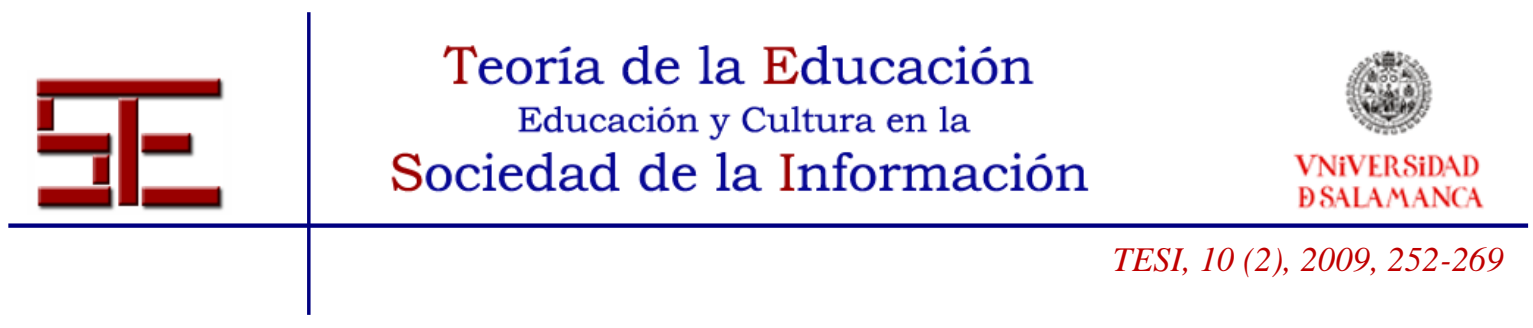

One could only remark, as it was indeed done, that we do see more involvement in the transfer or application of knowledge from computer science to the "arts" than evidence of the opposite, except maybe in its commercial aspect where external designs use appellations such "Picasso" tops. It is obviously evident that knowledge and expertise in computer and information technology has become essential to applied social, cultural and humanities qualitative research and the dissemination of its results. All present at the symposium agreed that progress is apparent, yet ideal team-research situations would require personnel equally qualified in at least two areas inclusive of computer science. Our experience in this domain has tended to see technically-minded "arts" students who would seek expertise in applied computer science and register into programmes such as "Multimedia" to expand their knowledge and apply it to such fields as ethnographic archival research and dissemination of textual, sound and visual primary data, as we will see in the case of the Léann Dúchais Leictreonach CD ROM example which I will describe at the end of this article.

Such reflection as that which arose from post-symposium debates and observation led by Stiofan Ó Cadhla from the department of Folklore and Ethnology at UCC estimated that an academically recognized qualification which would integrate both computer science and ethnographic studies from an applied perspective is becoming urgently necessary. It seems that much potential is wasted for the lack of resources available to humanities and social sciences academic departments who increasingly use ethnography as a method of investigation and whose field research output consists of the types of multimedia primary data such as oral interviews and video material which provide the essential support for analytical enquiry and theoretical construct.

While it is true that innovations such as the simplification and lesser costs of digital technologies have popularised their use and made them accessible to users other than computer scientists, academic and research units such as the Northside Folklore Project described below would undisputedly benefit from a systematic allocation of the required technical expertise. It is from within this emerging context of potentials offered by relatively accessible digital and information technologies that I will further outline and examine the extent and content of recent innovations from the perspective of their impact in new approaches to the collecting, archiving and disseminating of Folklore and Popular Culture in urban and rural settings as well as the study and teaching of Folklore and Ethnology at University College Cork.

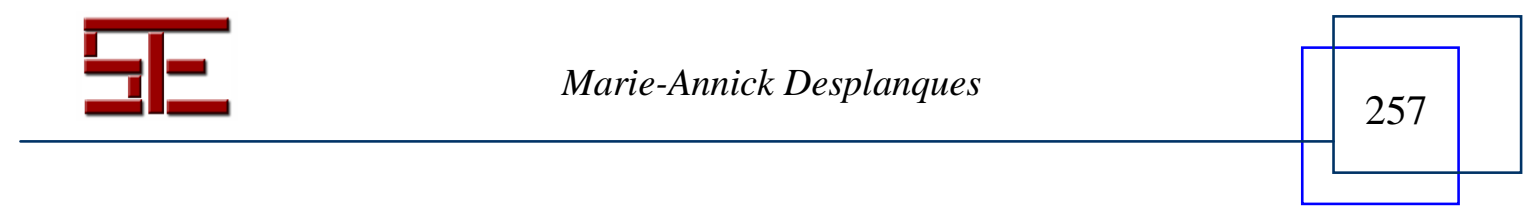




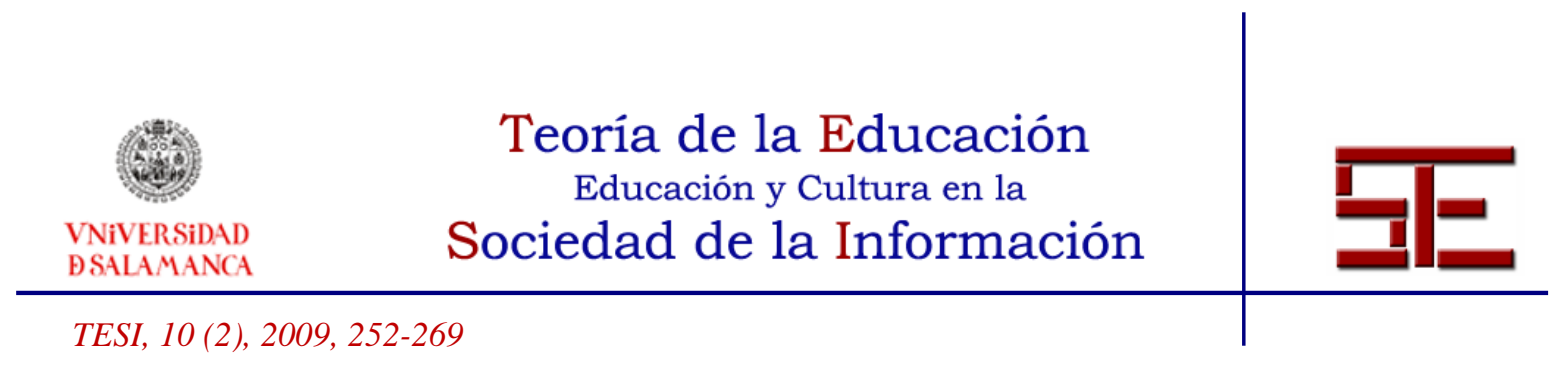

In order to proceed with this however, it is necessary to relocate the debate and topic within a theoretical and contemporary context of recent reflections and theoretical advents in the areas of Folklore and Popular Culture. Contemporary Information Society provides us with an operative context where the most private traditional culture performance occasions and arenas can easily be, although are not systematically, recorded and transmitted on to a public, albeit virtual, scene. The ensuing consequence of such mechanism implies that from the point of view of process and communication Folklore can no longer be totally dissociated from the potential influence of media technology and therefore potentially be assigned new meaning as it acquires new dynamics and operates among individuals from an eclectic array of backgrounds which nevertheless inform the makings of new, albeit virtual, communities.

\section{2. - FOLKLORE AND POPULAR CULTURE / THE MILLENNIUM BUG}

The role of media is intrinsically essential to the definition of both Folklore and Popular Culture. Media as an active operating factor provides "transmission" hence the connective dynamic that contributes to the formation of the collective and therefore the communal dimension from which and by extension through which, the notion of a sense of community derives. The other essential and intrinsic factor, being the notion of a sense of identity, consists in and considers effects and affects of relationships between individual members of groups partially constructed with affirmations and aspirations of belonging together. These relationships based on connected or as we will see "networked" forms of identification between and among individual members are experienced and expressed around meaningful aspects of commonly recognized symbolization and stylization.

Peter Narváez and Martin Laba, in their collection of essays Media Sense, introduce a sensatory dimension as a criterion of transmission and perception to differentiate between Folklore and Popular Culture while, establishing what they conceive of and term a continuum based on group size and degree of remoteness in contexts of performance. The nature of this sensatory criterion can be attributed to or defined by the mode of communication of the cultural item (Narváez, and Laba, 1986, 1). The emphasis therefore lies on process although it is never completely detached from the actual content of communication. Such content is itself either, or in turn, qualified and potentially classified as "lore" or "culture". It is around this "lore" or "culture" loaded item that identity is expressed and negotiated and that community is "artistically" constructed.

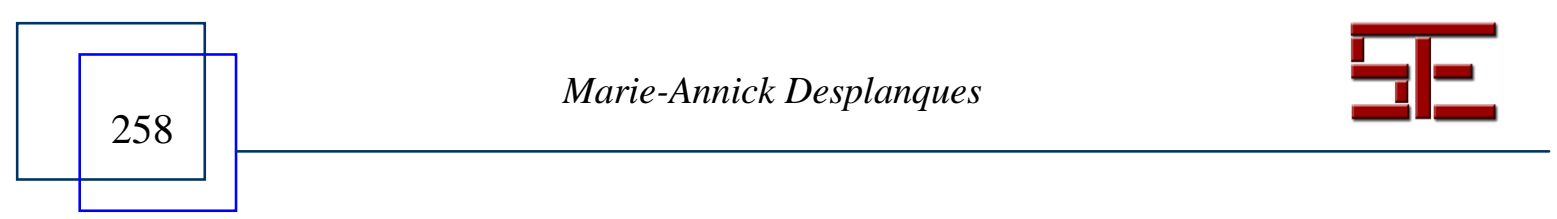




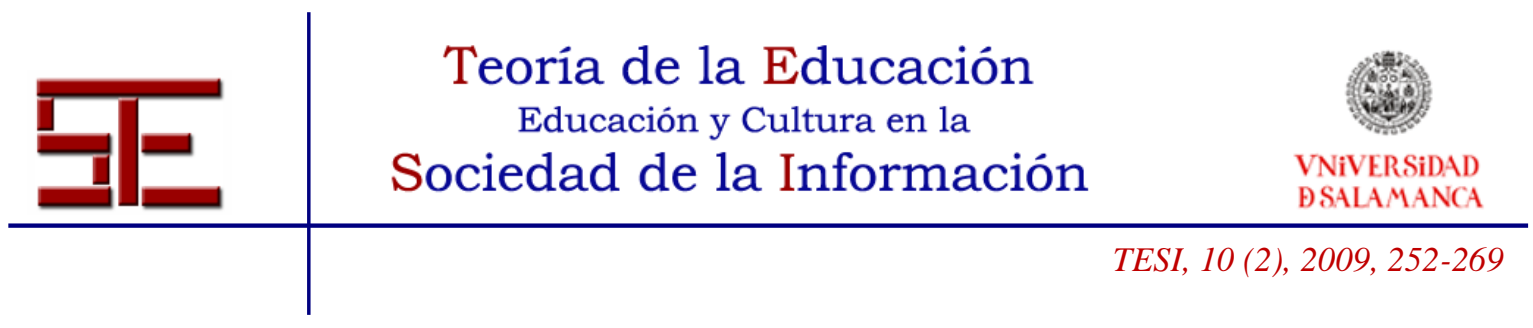

From this perspective, where both Folklore and Popular Culture hold qualities and properties of communally shared creativity and stylization, Peter Nárvaez and Martin Laba derive that Folklore stands at one end of the continuum and Popular Culture at the other with nevertheless inferences from each one to the other. To give examples of the nature of these inferences, the authors consider - in the case of Popular Culture inferring on Folklore: the influence of comic strips characters on schoolchildren's games. On the other hand, the uses of folktales-like motifs and structures in Hollywood movie productions are cited in example to illustrate the inferring relationship of Folklore on Popular Culture. (Narváez and Laba, 3). In both cases, the factors and criteria relating to group-size and mode of communication are noticeable and determining. The content "lore" or "culture" is therefore not singularly defined but rather, adapted to group size or mode of communication.

However and it interesting to note that the advent of network communication technology and the internet have had the capacity and the potential of transforming this presumably linear continuum established by Narváez and Laba into a full circle thanks to new developments in interactive communication technologies such as the internet. Thus it becomes possible for "artistic communication in small groups" a characteristic which is essential in the definition of folklore according to Dan Ben-Amos to combine with the specific uses of a mass media communication tool. This in itself becomes significant in the definition of Popular Culture in order to create virtual spatial or situational contexts (Ben-Amos, 1971). Such process then creates communities in which ritualized and stylized small group interaction can take place. This for instance is the case of internet based virtual "chat rooms" which by definition semantically give an impression of a small degree of proximity defining both the space-context and the stylecontent of the occurring interaction. We therefore have a performance event where the potential group situation and the awareness dimension inferred by the technology imply the presence of a performer and an audience (Ben-Amos and Goldstein, 1975).

The decade following the publication of Media Sense was extremely dynamic and productive. Significant progress and advent in communication technology and therefore theory came to the fore even if sometimes it may have appeared as accidental. It is nevertheless important to consider the consequences on the practice of ethnography and the teaching, learning and studying of Folklore and Ethnology at University College Cork.

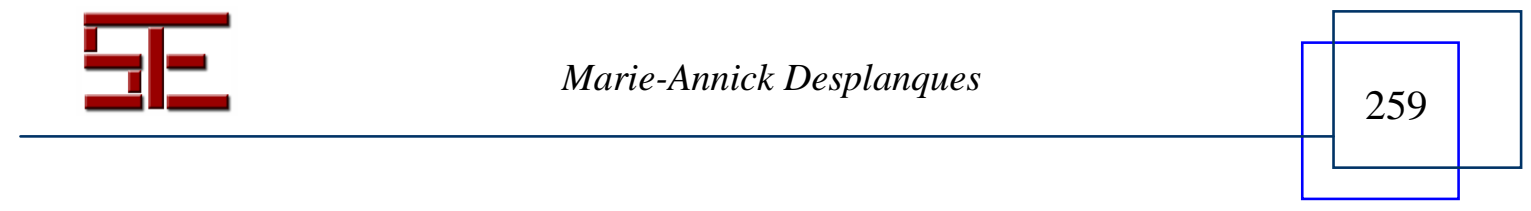




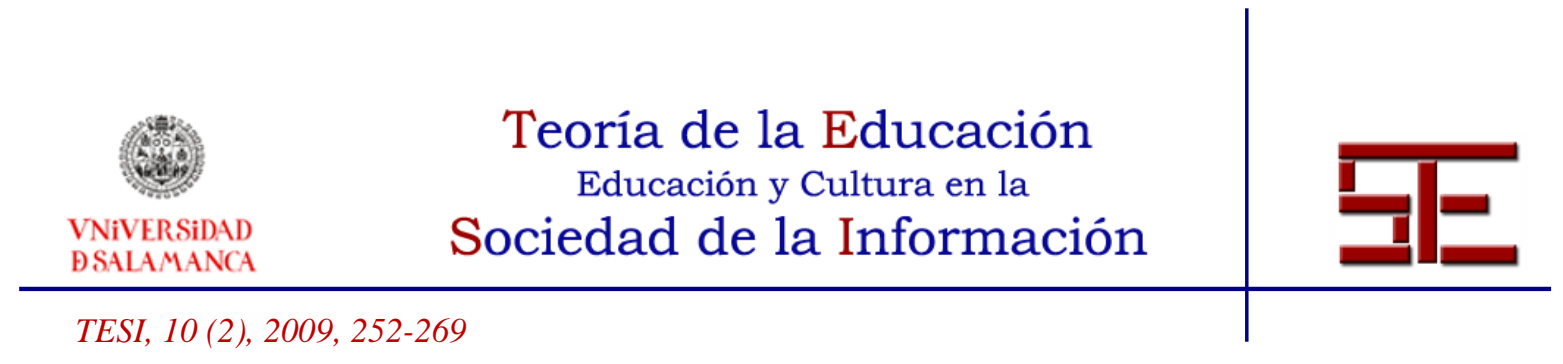

A Folklore and Popular Culture perspective cannot of course ignore the significance of such a calendar date as January 1 st 2000 , as it weres. When considering technological and computerized information systems and societies the universal impact of that particular calendar date was undeniable. We all recall the various stories, theories, practices, exercises and policies derived from variations and interpretations of what became globally known as "The Millennium Bug" phenomenon, which we may now agree to regard as an aspect of popular culture6. As such, the phenomenon generated its ample share of material which fit into a Folkloristic classification of knowledge, organized as follows: oral and printed literature, ritualized and structured customary practice and behaviour, as well as mainly computerized forms of micro technologies and software, one might consider as material culture productions. All these were enunciated, devised and designed to adapt and cope with a perceived situation with eventually became reality as it generated such above mentioned productions. This reality and its associated productions were essentially based on informal and intangible processes of dissemination of belief in a version of the "end of the world"(Ratto, 2005; Hoplight Tapia, 2002). Folklore and Popular Culture scholars could indeed generically classify and study the phenomenon as one typical of a modern legend, albeit a temporal one.

The reaction to the phenomenon was universal yet varied. It corresponded to the extent of the availability of computer technology and therefore affected all subgroups of Information Society. Furthermore the reaction to the phenomenon could possibly be evaluated in terms of graded perceptions and adherence ranging from total belief and acceptance to total disbelief and rejection, especially if one focused on versions and variations of individually expressed opinions and reactions (such a focus could generate a corpus of motifs which could be used in comparative studies). Generally speaking, institutions and organizations, belonging to what I refer to above as subgroups of Information society, therefore communities in their own right, took a cautious approach to the eventuality of the phenomenon, one akin to a "better safe than sorry" attitude. They therefore issued directives - now worthy of being considered as part of what Roland Barthes would call (urban) mythologies (Barthes, 1957), to pre-empt potential damage to computer systems and computerized data. As a result, new temporal communities started to emerge, made of "millennium bug" specialists whose jobs, because jobs were actually created, were to devise anti-bug programmes and special computer updates. The phenomenon produced ample literature, virtual and otherwise. Most of the material and programmes referred to above, as well as the communities which emerged as a result are still visible, if not dormant, for the majority; One simply

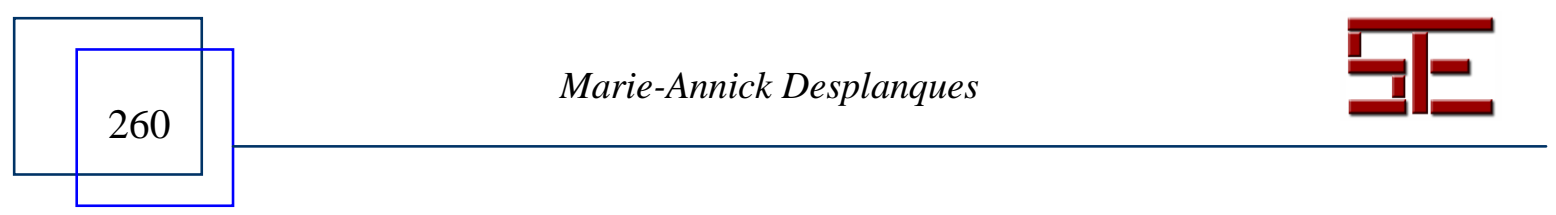




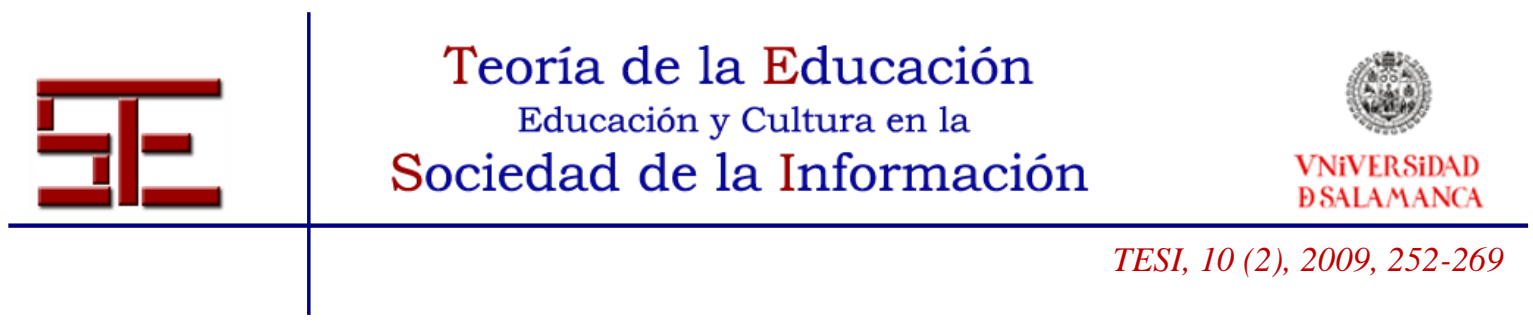

need to enter the term "Millennium Bug" into any computer search engine to see the number of references to websites and publications and therefore measure the impact of the phenomenon, eventhough it is now part of the "history" of popular culture as much is indeed written from that perspective.

At the time, The Millennium Bug, also associated to what was popularly known as "Y2k", meaning Year 2000, however, had coincidental impact for the University College Cork Folklore and Ethnology Archive (UCCFEA) and the Northside Folklore Project (NFP), (Desplanques, 2005). It became the opportunity to actually systematize and integrate the catalogues of the two archives into computerized "safe" and userfriendly databases with online search facilities. Previous to this, the catalogues were organized and kept in a combination of mechanically typed index cards and computerized text files where dates were entered in a two digit mode, as in for instance 60 instead of 1960. It has to be noted that the gist of the Millennium Bug scare, was that on January 1 st 2000 , computers would lose all the data associated with 00 as an entry for 2000. It was deemed that this systemic confusion would result into an annihilation of all files dated as 00 . This of course is a very simplistic interpretation of the phenomenon, but it certainly prompted us to pay attention and indeed consider re-dating the archival entries in a four digit mode when transferring the text documents in a database format, which interestingly enough was later partially abandoned by the computer scientists who transferred the data online and still at the time of writing transforming the final website mentioned below.

An initial example of the result of the database integration exercise was sampled to become part of the Higher Education Authority (HEA) funded Documents of Ireland (DOI) project which combined search engines for data covering all aspects of humanities research and including nine documental research projects. These were based in such academic disciplines as Archaeology, History, Geography, Ancient Classics, Irish and Folklore \& Ethnology.7 This particular research programme also enabled the creation of a new project: a virtual centre of archival research which integrated not only the catalogues but also the contents of the archival collections of both UCCFEA and NFP into the Multimedia Centre for Urban and Regional Ethnology (MCURE)8. With the implementation of MCURE the potential for exploring the educational dimension of these new information technology advents and their applications opened yet new avenues and directions for our expanding team of researchers.

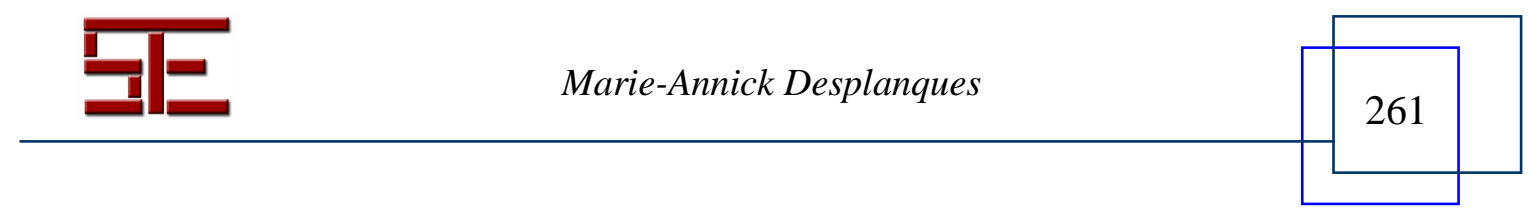




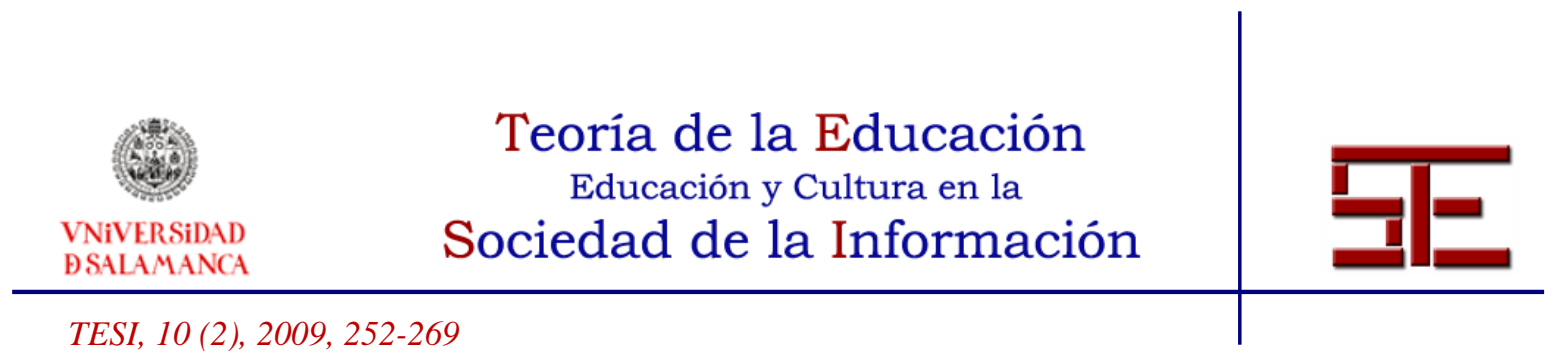

\section{3. - THE MULTIMEDIA CENTRE FOR URBAN AND REGIONAL ETHNOLOGY}

This MCURE project received funding from the Higher Education Authority from 1999 until 2002 through Documents of Ireland, under the Programme for Research in Third Level Institutions (PRTLI)9. In Parallel and on behalf of the Northside Follklore Project strand of MCURE I also applied and within a year received further funding through another HEA programme called "Targeted Initiatives" with a typically educational dimension and involving the Centre for Adult and Continuing Education at University College Cork. This was on the strength of the integration of the Northside Folklore Project into MCURE which to a certain extent reinforced its mission to give it an Adult Education agenda, as NFP involved FÁS, the government training and employment agency, as one of its partners.

One may argue that academic recognition through this type of funding enhanced the status of MCURE and the then newly created Department of Folklore and Ethnology social and community ethos in a manner akin to that of the Infobrion project in Galicia This latter project also integrates academic research and community applications through the uses of ethnographic material. During their visits to the department of Geography and the library at UCC and thanks to the interdisciplinary dimension and contacts made through the Documents of Ireland Project, Carlos Ferrás Sexto, Yolanda García Vasquez and Carlos Macía Arce became interested in the work of MCURE and of the Northside Folklore Project. As research director of NFP and principal initiator of MCURE, I had the privilege to meet with them, exchange ideas, research models and cooperation ensued through mutual visits, conferences and publications (Ferrás, 2005; Ferrás et al, 2006).

Thus, the extra funding mentioned above was obtained on the strength of educational applications and potentials. It essentially guaranteed the possibility of keeping the then precarious positions of the Northside Folklore Project research coordinator and manager afloat, which in turn enabled the continuing of NFP's research and archival activities. These included an issue increase of the regular publication of the NFP journal The Archive, and it distribution in Cork city and beyond. The journal also eventually became available online. Internal UCC interdepartmental contacts created through the "all exchange" UCC computer network allowed MCURE to become aware and foster the research of postgraduate students in the department of computer science "multimedia"

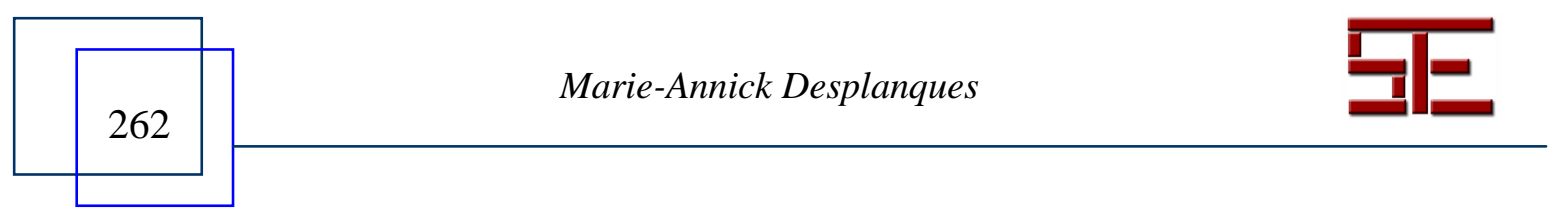




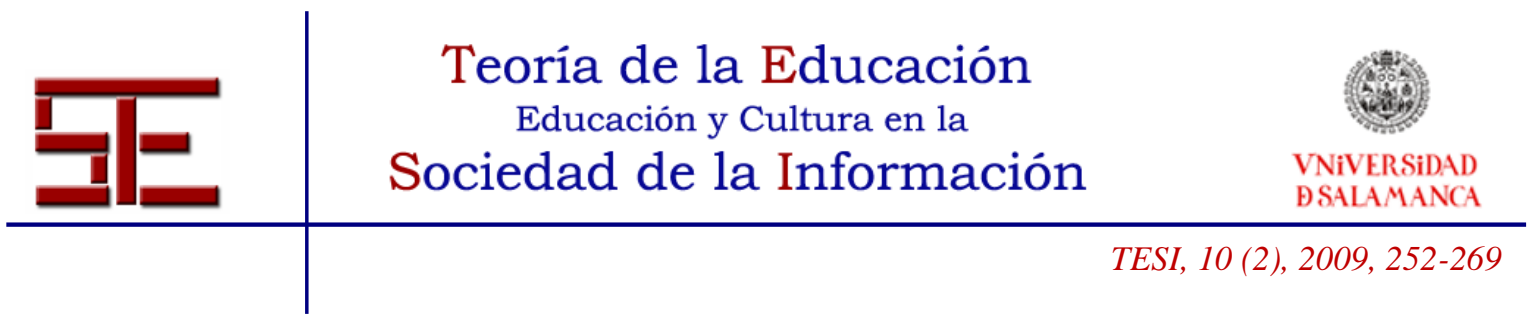

programme. Through a "students project" scheme developed by Ian Pitt, then head of the computer science "multimedia" programme, NFP offered a research environment for these dedicated postgraduates to develop an early version of the "in-house" NFP database. Most importantly they devised the NFP internet website which included access to the photographs and sound recordings catalogues as well as samples of the photographic collections and publications of the newly integrated project.

The combination of all these developments in information technology at University College Cork gave MCURE the necessary visibility to engage into further research and partnerships with and outside University College Cork, essentially with the Heritage

Council of Ireland, the UCC based Coastal and Marine Resource Centre and also internationally with the Memorial University of Newfoundland Folklore and Language Archive (MUNFLA) through funding obtained from the Ireland-Newfoundland Partnership. I will come back to the specific educational value of these projects at a later stage. The idea of integrating the catalogues of both archival repositories was therefore driven by the available HEA funding and implemented through the participation of the then Centre for Folklore and Ethnology into the Documents of Ireland Project. It resulted in the establishment of a Research Centre of excellence to further the integration of the regional and urban research activities of academics and students in the department of Folklore and Ethnology at University College Cork with those of the Northside Folklore Project.

Based on both the theoretical premises in Ethnology which outline the necessity of an insider/outsider approach to ethnographic research and on its application to a growing demand for community-based research and resources, MCURE addresses issues which range from the collection of data to its archiving and dissemination.

\section{1. - The Northside Folklore Project}

The urban ethnology section of the project consists of the Northside Folklore Project research team comprising of local researchers who are paid by the Irish Government Training and Employment authority also known as FÁS, (an acronym which sounds like the verb "to grow" in Irish). The project is housed in Cork city at Northside Community Enterprises (NCE) and the researchers are trained by the UCC ethnologists in field collection and archival practice. They identify, describe and record aspects of the worldview and lifestyle of Cork city communities so as to throw light on the cultural and social processes that underline the daily life experiences of city dwellers and users.

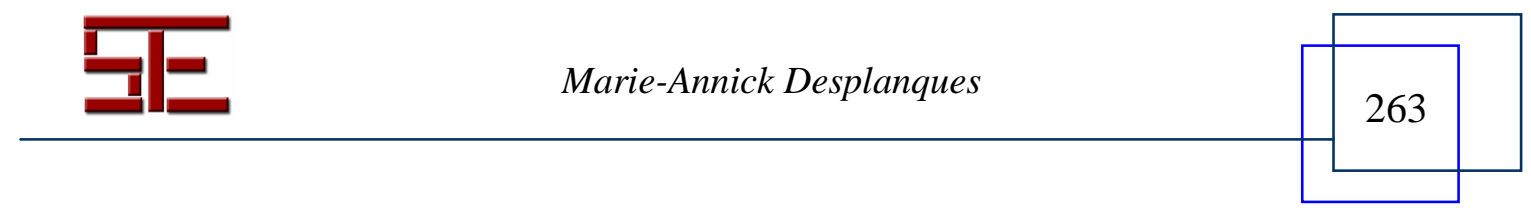




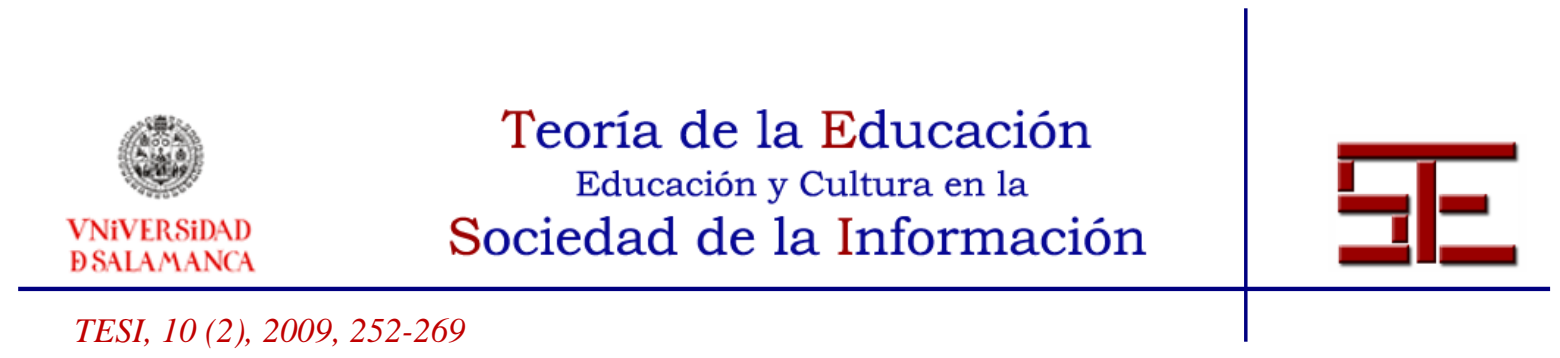

This is done especially in relation to the representation and expression of cultural identities in local contexts of performance and to the larger society through vehicles of farreaching communication systems such as traditional radio and television broadcast or the internet. Thus the NFP branch of MCURE seeks to investigate the ways in which Cork identity and collective self-image are constructed, contested, defended, renewed and transmitted within a cultural process that itself dynamically reflects people's actual experience of social and cultural life. The multimedia formats of NFP publication output, reflects not only the diverse content of the collections, but also and most importantly, the impact and potential democratizing dimension of digital technologies, both in terms of its readiness of access, handling and uses. The NFP further integrates the insider/ outsider perspective by functioning as a training and fieldwork ground for college students, school goers and international students through its UCC sponsored internship programme which so far has enrolled North American and Australian visiting anthropology students who contributed fresh and different perspectives to the collections of the archive.

\section{2. - The UCC Folklore and Ethnology Archive}

The UCC based Folklore and Ethnology Archive, the academic branch of the project, holds both primary data and their analytical interpretation as this arises from students' projects and theses. This archival repository thus preserves not only the primary ethnographic material but also aspects of the intellectual history of the discipline of Ethnology.In addition the UCCFEA collection also carries material relevant to and documenting rural and regional folklore and traditional culture. Therefore to a certain extent, it expands on the essentially urban character of the Northside Folklore Project collection. Furthermore, although UCCFEA has only been established since 1995, a year previous to the start of collecting and archival activities at NFP, the time span of the UCCFEA documents nevertheless goes back to the foundation of the first courses in Folklore at University College Cork in 1977.

Using the same cataloguing structures, UCCFEA provides the regional dimension of MCURE. Its collection of ethnographic data therefore extends to most areas of County Cork and other Munster Counties, especially Kerry. Additional material originates from other parts of Ireland and indeed Europe and North America but to a much lesser extent. This is representative of the origins of the student population as they are the main collectors. This regional dimension coupled with the fact that the department also

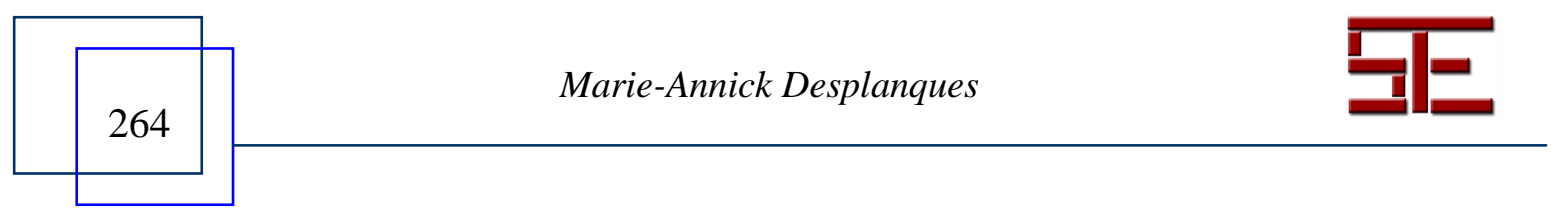




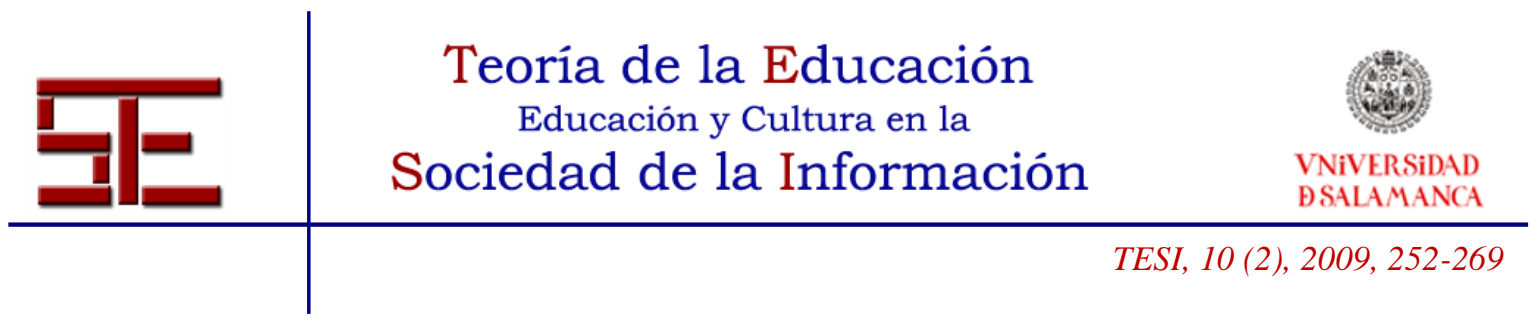

teaches the subject through the medium of Irish as An Léann Dúchais implies that a great part of the UCCFEA ethnographic collections come from An Gaeltacht.

The implications in terms of access and educational potentials are dual. The similarities of the cataloguing structures as we have seen above, allows for the virtual integration of the material in searchable websites such as Documents of Ireland. Furthermore it also has beneficial consequences on the applied dimension of fundamental research and more particularly on the role of the University in the Community. Just as the Northside Folklore Project functions as a field station and research archive for the academic community, the UCCFEA also serves as a training ground for the researchers employed by the NFP. There is therefore a dynamic established between the two research facilities which ultimately enhances awareness, visibility and therefore the role and status of Folklore and Ethnology as an academic discipline with a strong applied dimension.

\section{4. - EXTERNALIZATIONS OF ETHNOGRAPHIC RESEARCH.}

Electronic media and computer applications and technologies have been essential in the dissemination and therefore the provision of access to the ethnographic material generated by the Northside Folklore Project and the University College Cork Folklore and Ethnology Archive. As mentioned above the multimedia publications of the NFP consist of print, sound and video material which addresses urban cultural environments and are accessible in their original formats and through "traditional" media such as print, radio, television or cinema. One can argue that these formats render the performance occasional and eventual. The documents are also however accessible via the internet and through the NFP website which to an extent generalizes if not democratizes dissemination as access is technically available at all times and on an individual or personal mode. Similarly the UCCFEA has generated multimedia CD ROMS based on educational applications of its Irish ethnographic collection. The example described below presents and discusses the elaboration of the Léann Dúchais Leictreonach (LDL) since 2001.

As is suggested by its acronym the LDL project aimed to use advents in communication technology to enhance the availability and the dissemination of ethnographic research and resources relevant to the content and teaching of An Léann Dúchais. A strand of the HEA targeted initiatives programme more specifically dealing with "the teaching of a subject other than Irish through the medium of Irish" itself allowed for an eventually productive collaboration of several departments and spheres of expertise at UCC.

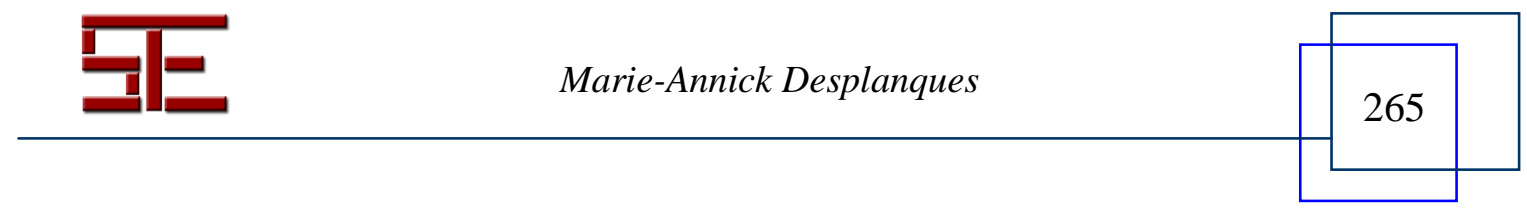




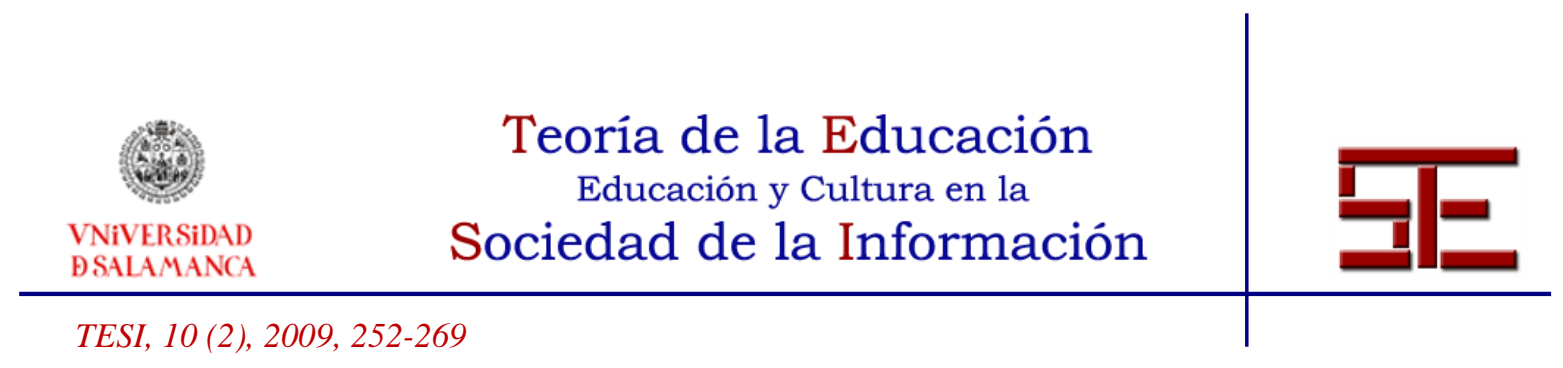

This interdisciplinary approach however was by no means foreign to the department of Folklore and Ethnology but rather a logical extension of its affiliation to and participation in other teaching programmes in Heritage Management, Local and Regional Studies, Women Studies, and most importantly to significant research projects such as the above mentioned Documents of Ireland, Breaking the Silence9 and Women in Society10 which involved several department in the Humanities, Social Sciences and Computer Science.

The dual mission of the department of Folklore and Ethnology at UCC, consists in delivering a full curriculum in two ethnology subjects, one of which, An Léann Dúchais, through the Irish language sourcing its main referent data from the legacy and the dynamic production of Irish language ethnographic material in textual, aural, visual and audio visual formats, with substantial contributions from the UCC Folklore and Ethnology Archive. Distinct from the Folklore and Ethnology programme per se, An Léann Dúchais carries an interdisciplinary dimension and focuses on cultural studies and bilingualism. Strong intellectual links therefore exist with all other Irish Language departments at UCC.

The teaching aid CD ROM which will eventually be available as a website to UCC students comprises of three first year modules and is the result of extensive dedicated research and productive synergies from an extremely competent team of individuals coming from versatile intellectual backgrounds and areas of expertise. All involved however have had and maintain connections with the department of Folklore and Ethnology, whether they are part of the teaching staff, or former students who subsequently fostered interest and specialised in computer science, or were initially involved in the Northside Folklore Project where they gained not only ethnographic and archival knowledge but also developed sound and video editing as well as publishing and graphic design expertise.

Beyond its obvious contribution to the development of electronic teaching resources, the LDL project is therefore a primary and successful model for the integrative applied dimension of a discipline too often confined by popular imagination as being bookish and old-fashioned.

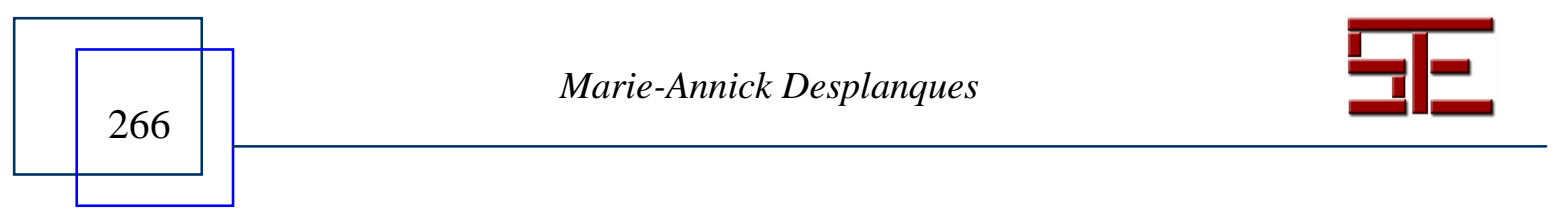




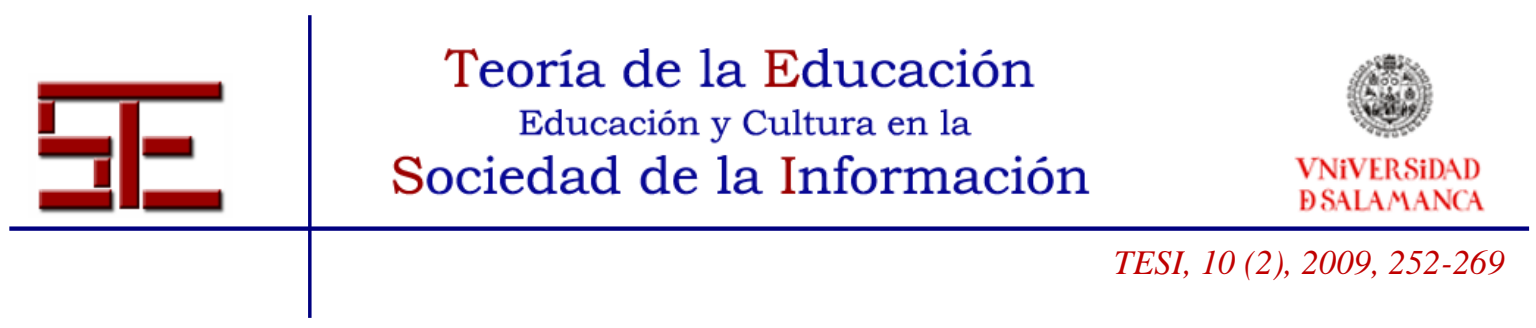

\section{5. - CONCLUSIONS}

Having explored and presented a variety of examples and issues relating to popular culture, overseeing its contents to prioritise its processes and media of communication, one can focus on an educational perspective and consider the dynamic plurality of the types of materials and search facilities offered by the Documents of Ireland, website as an example of how digital and information technologies combine to allow for the immediate integration of previously isolated academic perspectives. The particular case of the ethnographic archival catalogues and excerpts made available through the virtual Multimedia Centre for Urban and Regional Ethnology including the heritage and repertoires sampled on the autonomous Northside Folklore Project website show that digital technologies allow for the increased dissemination of cultural data and to an extent enhances the democratisation of information society. By doing so, it popularizes access to archival material. These examples as well as other productions from the department of Folklore and Ethnology at University College Cork such as the Léann Dúchais Leictreonach CD ROM form the basis of extensive research in the computer applications available to ethnographers and are only a fraction of the potentials information technology may have on the development of theoretical perspectives and analysis pertaining to new considerations and understandings on issues of communities and identity and the role of individuals within.

Further avenues of fundamental and indeed applied research and creativity open up as technologies improve to become increasingly participatory and interactive. Will "my space", "u-tube", "second life", "share ware", and other virtually designed modes of communication become essential networks in which community and identity markers will further depend on access and availability to commercially produced and distributed software and its unavoidable derogation? The rapid expansion and globalisation of information society generate extensive networks of "sub-cultures" based on the potentials offered by the creative manipulation of digital and computer technologies. In turn, this process forever and constantly changes and re-directs ethnographers' fields of enquiry. New theoretical perspectives and philosophies are bound to emerge as new sets of symbols and values (semiotic and semantic) derive from these technological advents.

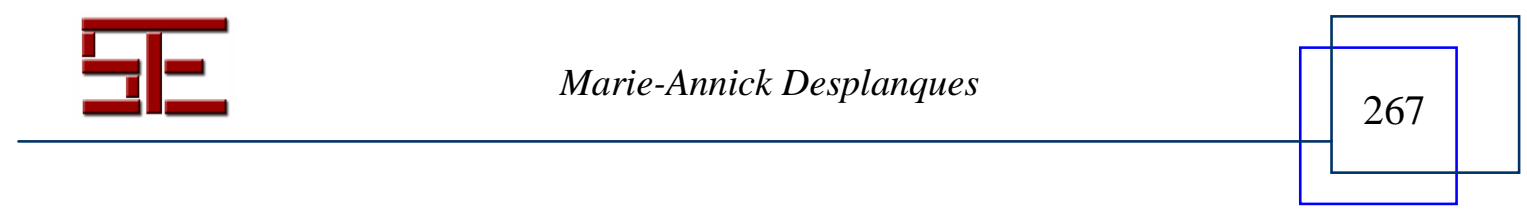




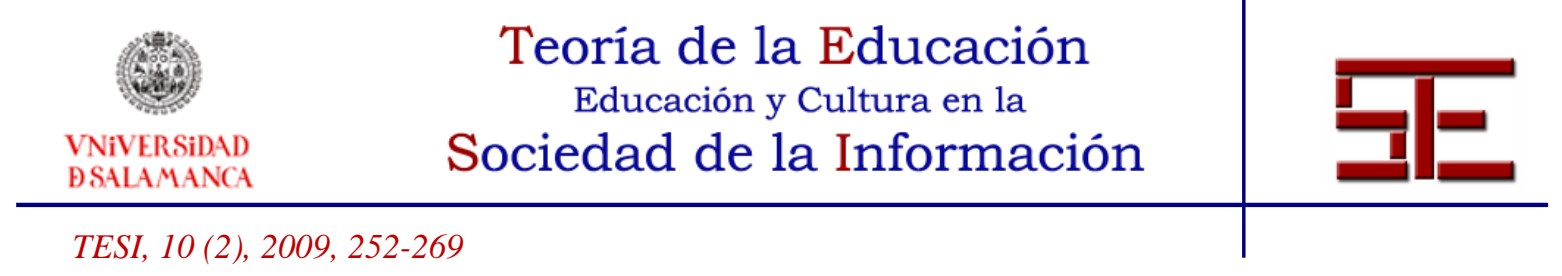

\section{BIBLIOGRAPHY}

BARTHES, R. (1957): Mythologies. Paris, Seuil.

BEN -AMOS, D. (1971): Toward a definition of folklore in context, Journal of American Folklore, 84, 3-15.

BEN -AMOS, D. and GOLDSTEIN, K. eds. (1975): Folklore, Performance and Communication. La Hague, Mouton.

HOPLIGHT TAPIA, A. (2002): Techno-Armageddon: the millennial christian response to Y2K, Review of Religious Research, 43 (3), 266-286.

DESPLANQUES, M-A. (2005): The Northside Folklore Project. A case study in applied social ethnology, in FERRAS SEXTO, C. (ed). Novas Tecnoloxías e Economía Cultural. II Xornadas SINDUR Santiago de Compostela, Servizo de Publicación, 29-51.

DESPLANQUES, M-A. and O' CARROLL, C. (2006): Cultures of Cork: community, ethnicity and broadcasting, in. FERRÁS SEXTO, C., ARMAS QUINTA, F.

MACIA ARCE, X. and GARCIA VAZQUEZ, Y. (eds). Sociedade de Informacion en Espacios Periféricos Novas Formas de Exclusión Social. Santiago de Compostela, Servizo de Edición Dixital da Universidade de Santiago de Compostela, 107-114

FERRAS SEXTO, C. ed. (2005): Novas Tecnoloxías e Economía Cultural. II Xornadas SINDUR Santiago de Compostela, Servizo de Publicación

FERRAS SEXTO, C., ARMAS QUINTA, F., MACIA ARCE, X. and GARCIA VAZQUEZ, Y. eds. (2006): Sociedade de Informacion en Espacios Periféricos Novas Formas de Exclusión Social. Santiago de Compostela, Servizo de Edición Dixitalda Universidade de Santiago de Compostela.

NARVÁEZ, P. and LABA, M. eds. (1986): Media Sense. Bowling Green, Bowling Green State University Press.

RATTO, M. (2005): Don't fear the penguins: negotiating the trans-local space of linux development, Current Anthropology, 46 (5), 827-834.

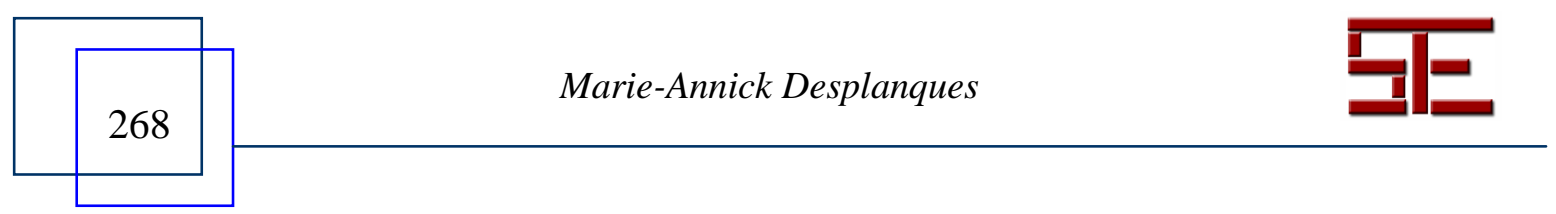




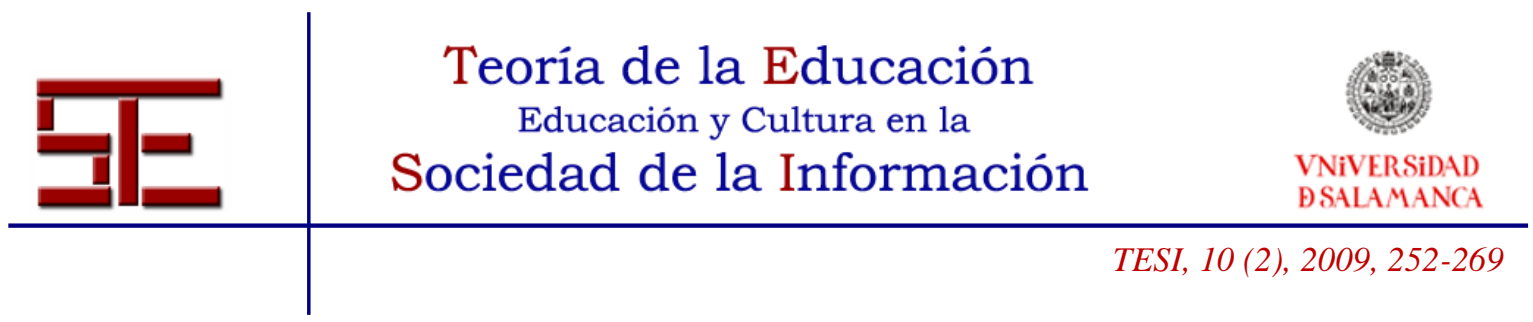

SÓLEYJARSON, Ó. G. (2008): Missing man: death in an online world. Beascna, 4, 112-124.

WELLMAN, B. and GULIA, M. (1999): Virtual communities as communities: net surfers don't ride alone, in SMITH M. A. and KOLLOCK, P. (eds.) Communities in Cyberspace. New York, Routledge, 167-194.

\section{Notas:}

1 Marie-Annick Desplanques, "Creating Resources in Digitised Ethnography: The Multimedia Centre for Urban and Regional Ethnology." Digitising Ethnography Symposium, University College Cork, 2006.

2 The Project "How's it Goin' Boy?" consists of a series of six radio programmes produced by Cliona O' Carroll for the Northside Folklore Project.

3 See: Breda Gray's project Breaking the Silence: staying 'at home' in an emigrant society http://migration.ucc.ie/oralarchive.htm

4 The presentations given at the symposium were recorded and are available for consultation at the University College Cork Folklore and Ethnology Archive.

5 Year 2000 reflects a western point of reference which is not inclusive of the diversity of calendar systems around the world, but which nevertheless had a worldwide impact.

6 The Millennium Bug referred to a computer virus which would damage information systems resulting in the potential loss of all data once computer clocks reached midnight on December 31 st 99 to turn to 00-

$00-00 ! ! !$

${ }_{7}$ Go to: http://doi.ucc.ie/

${ }_{8}$ Go to: www.ucc.ie/folklore

1 The application to the HEA was compiled by the author in consultation with Gearóid Ó Crualaoích, then head of Folklore and Ethnology at University College Cork.

${ }_{9}$ Go to: http://migration.ucc.ie/oralarchive/testing/breaking/index.html

${ }_{10}$ Go to: http://www.ucc.ie/wisp/ohp/index.html

Para citar la presente editorial puede utilizar la siguiente referencia:

Desplanques, M. A. (2009). Digitizing tradition: aspects of the applied dimension of urban and regional ethnography in Irish, en Ortega Sánchez, I. y Ferrás Sexto, C. (Coord.) Alfabetización Tecnológica y desarrollo regional. Revista Electrónica Teoría de la Educación: Educación y Cultura en la Sociedad de la Información. Vol. 10, no 2. Universidad de Salamanca, pp. 252-269 [Fecha de consulta: dd/mm/aaaa]. http://campus.usal.es/ revistas_trabajo/index.php/revistatesi/article/view/7516/7548

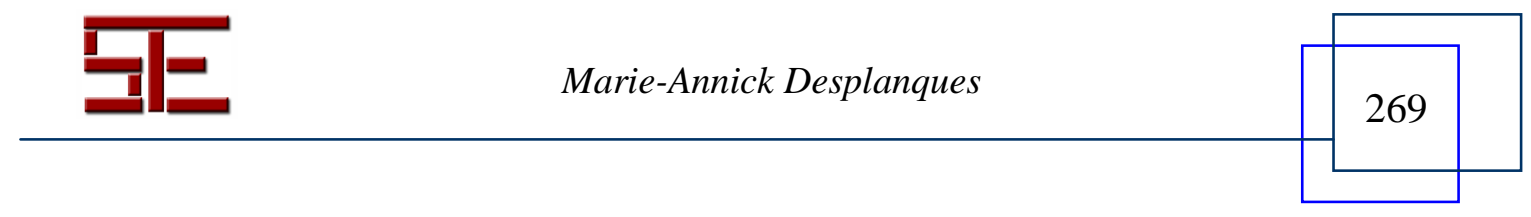

